\title{
CONCEPÇÕES E PERSPECTIVAS DA AVALIAÇÃO DE APREN- DIZAGEM: UMA REVISÃO ANALÍTICA
}

\author{
CONCEPTS AND PERSPECTIVES OF LEARNING ASSESSMENT: a review ana- \\ lytical
}

\author{
CONCEPTOS Y PERSPECTIVAS DE LA EVALUACIÓN DEL APRENDIZAJE: una \\ revisión analítica
}

\author{
Vilma Bragas Oliveira \\ Professora Doutora da Universidade Federal do Maranhão (UFMA). \\ Departamento de Licenciatura em Ciências Naturais, campus São Bernardo. \\ vilbragas@hotmail.com
}

\begin{abstract}
RESUMO: A avaliação constitui-se parcela primordial do processo ensino aprendizagem sendo o principal instrumento diagnóstico para o conhecimento da realidade cognitiva, intelectual e formativa de um grupo. Desenhar um retrato diagnóstico da avaliação de aprendizagem através das experiências descritas em artigos, comunicações, relatos e documentos relacionados é o objetivo desse trabalho de revisão. Pelo levantamento realizado percebe-se que pouco ou nenhum avanço foi concretizado nos últimos anos relacionados à mudança de postura frente aos processos de avaliação adotados nas mais variadas realidades educacionais. Além disso, pretende-se estimular os envolvidos nos processos avaliativos pela promoção de uma conscientização de que os métodos descritos na literatura e as recomendações realizadas em documentos oficiais são passiveis de sucesso e que os mesmos não são utópicos, mas reais.
\end{abstract}

PALAVRAS-CHAVE: Avaliação de Aprendizagem. Diagnóstico. Ensino-Aprendizagem.

ABSTRACT: Evaluation is it crucial part of the learning process is the main diagnostic tool for understanding the cognitive reality and intellectual formation of a group. Draw a picture diagnostic of the evaluation of learning from the experiences described in articles, communications, reports and related documents is the aim of this revision work. In the survey perceive that little or no progress has been achieved in recent years related to the change of attitude in relation to the evaluation processes adopted in various educational realities. In addition, it is intended to encourage those involved in the evaluation processes by promoting an awareness of the methods described in the literature and the recommendations made in official documents are capable of success and that they are not utopian but reals. KEYWORDS: Learning assessment. Diagnosis. Teaching and learning.

RESUMEN: La evaluación es parte crucial del proceso de aprendizaje en lo cual es la principal herramienta de diagnóstico para la comprensión de la realidad cognitiva y la formación intelectual de un grupo. Hacer un dibujo de la evaluación diagnóstica de aprendizaje de las experiencias descritas en los artículos, comunicaciones, informes y documentos relacionados es el objetivo de este trabajo de revisión. La encuesta perciben que se ha logrado poco o ningún progreso en los últimos años relacionados con el cambio de actitud en relación con los procesos de evaluación adoptados en diversas realidades educativas. Además, se pretende animar a los que participan en los procesos de evaluación mediante la promoción de una conciencia de los métodos descritos en la literatura y las recomendaciones formuladas en los documentos oficiales son capaces de tener éxito y que no son una utopía, pero real.

PALABRAS CLAVE: La Evaluación del Aprendizaje. Diagnóstico. La Enseñanza-Aprendizaje.

$\overline{\text { Artigo recebido em maio de } 2016}$

Aprovado em julho de 2016 


\section{1| INTRODUÇÃO}

Avaliar consiste do ato de mensurar, medir, dimensionar, quantificar ou qualificar algo que se deseja atribuir valor ou grau; é o ato de diagnosticar. Para esse fim são aplicados métodos, instrumentos e ferramentas que devam ser pensados de forma a se adequar ao objeto, fato ou fenômeno a ser avaliado.

No contexto educacional o livro de Introdução aos Parâmetros Curriculares Nacionais para o ensino de $1^{\circ}$ a $4^{\circ}$ série realiza propostas sobre a avaliação em cada momento da escolaridade e em cada área, envolvendo questões relativas a o quê e como avaliar, realizando um desenho com orientações para avaliação, critérios de avaliação, decisões associadas aos resultados da avaliação e as avaliações oficiais: boletins e diplomas, e é considerada como elemento favorecedor da melhoria de qualidade da aprendizagem, deixando de funcionar como arma contra o aluno e sendo assumida como parte integrante e instrumento de auto-regulação do processo de ensino e aprendizagem, para que os objetivos propostos sejam atingidos. Nesse sentido, a avaliação diz respeito não só ao aluno, mas também ao professor e ao próprio sistema escolar (BRASIL, 1997a). Ainda no contexto educacional para o Ensino Fundamental os Parâmetros Curriculares Nacionais indicam critérios de avaliação das aprendizagens fundamentais a serem realizadas em cada ciclo e se constituem em indicadores para a reorganização do processo de ensino e aprendizagem. Tais critérios, porém, não devem ser confundidos com critérios de aprovação e reprovação de alunos (BRASIL, 1998a).

O documento Parâmetros Curriculares Nacionais - Ciências Naturais para o ensino de primeira a quarta série relata que até a promulgação da Lei de Diretrizes e Bases da Educação, a 4.024 em 1961, o cenário escolar era dominado pelo ensino tradicional e que aos professores cabia a transmissão de conhecimentos acumulados pela humanidade por meio de aulas expositivas, e aos alunos, a absorção das informações, que o conhecimento científico era tomado com o neutro e não se punha em questão a verdade científica, e a qualidade do curso era definida pela quantidade de conteúdos trabalhados, cujo principal recurso de estudo e avaliação era o questionário, o qual os alunos deveriam responder detendo-se nas ideias apresentadas em aula ou no livro-texto escolhido pelo professor (BRASIL, 1997b). O norte inicial trazido neste documento a respeito de avaliação é que coerentemente à concepção de conteúdos e aos objetivos propostos, a avaliação deve considerar o desenvolvimento das capacidades dos alunos com relação à aprendizagem de conceitos, de procedimentos e de atitudes, em contraponto ao que tradicionalmente ainda é realizado, na qual a avaliação restringe-se à verificação da aquisição de conceitos pelos alunos, mediante questionários nos quais grande parte das questões exige definições de significados (BRASIL, 1997b).

Segundo os Parâmetros Curriculares Nacionais do Ensino Fundamental de $5^{\circ}$ a $8^{\circ}$ série, a avaliação é um elemento do processo de ensino e aprendizagem que deva ser considerado em direta associação com os demais, informando ao professor o que foi aprendido pelo estudante $e$ ao estudante quais foram seus avanços, dificuldades e possibilidades. Além disso, deve conduzir o professor para a reflexão sobre a eficácia de sua prática educativa e, desse modo, orientar o ajuste de sua intervenção pedagógica para que o estudante aprenda (BRASIL, 1998b). Possibilita também à equipe escolar definir prioridades em suas ações educativas.

O cenário escolar têm sofrido grandes transformações, tanto no que se refere ao domínio e aplicação de recursos didático-pedagógicos mais modernos e atuais quanto na velocidade de veiculação e absorção de informações e conhecimentos e os processos avaliativos não podem ficar à margem desses avanços. Os PCNs desenham com eficácia o que seria uma avaliação de aprendizagem humanizada e comprometida verdadeiramente com a evolução da aprendizagem e 
do desenvolvimento cognitivo do aluno. Apesar disso, ainda hoje há um desprendimento do processo ensino-aprendizagem do processo avaliativo, quando na verdade os dois são parte de um todo.

Atualmente, é senso comum que os métodos avaliativos estejam intimamente relacionados aos instrumentos, recursos pedagógicos e métodos de ensino utilizados pelos docentes e que os resultados destas devam descrever além das dificuldades e deficiências da aprendizagem dos alunos, as dificuldades e deficiências dos docentes, fato que torna a avaliação não apenas um mecanismo classificatório, mas um instrumento diagnóstico do conjunto do processo de ensino aprendizagem, porém é recorrente dentre os educadores um discurso diferente da prática, no qual o processo avaliativo ainda é ditado pelo chamado ensino tradicional não representando os conceitos modernos já tão difundidos.

Dessa forma, este artigo tem por fim realizar um levantamento dos trabalhos relacionados a experiências de avaliação realizadas em variadas realidades de ensino - do Ensino Fundamental ao Ensino Superior - que possam levar os profissionais da educação a desenvolverem um senso autocrítico dos processos avaliativos até então utilizados e uma visão moderna do que os processos avaliativos devam objetivar. Para este fim, foram selecionados trabalhos que apresentassem resultados concretos da aplicação de métodos avaliativos. Os trabalhos selecionados foram organizados inicialmente pela aproximação com a proposta de discussão, depois pelas suas propostas metodológicas, se genéricas ou específicas.

\section{2 | EXPERIÊNCIAS DIAGNÓSTICAS GENÉRICAS DE AVALIAÇÃO DE APRENDIZAGEM}

Neste primeiro tópico, apresentamos a avaliação da avaliação, ou melhor, experiências diagnósticas dos processos avaliativos que nos ajudaram a traçar um perfil da realidade avaliativa presente em alguns cenários educacionais. Inicialmente, foi desenhado um retrato do processo avaliativo vigente nos mais diversos ambientes educacionais registrados em veículos variados nos últimos dez anos realizados por pesquisadores da área baseado em suas experiências na prática docente ou investigações realizadas em ambientes nos quais atuaram como observadores. Os relatos aqui descritos retratam em sua maioria um modelo de ensino por transmissão/ assimilação no qual os critérios de avaliação não são discutidos com os avaliados e os objetivos dessa avaliação são em sua maioria classificatória e excludente. Além disso, a maioria dos casos relatados retrata a incoerência entre o discurso e a prática docente.

No ensino técnico, uma pesquisa desenvolveu-se tendo como sujeitos quinze (15) professores e noventa e um (91) alunos da $1^{a}$ a $3^{a}$ série do CEFET - PI. A análise dos dados obtidos permitiram os pesquisadores constatar a coexistência de duas concepções contraditórias a respeito da avaliação. Uma chamada avaliação tradicional, predominante, em que o professor se coloca como aquele que ensina, e o aluno, como um ser passivo, que aprende à luz de uma abordagem que usa a "medida" através de uma prova que atribui uma nota, que, por si só, não produz dados suficientes para rever ou reformular o processo, se necessário fosse. Em contraposição a esse enfoque, emerge do discurso de alguns docentes, a avaliação construtivista-interacionista na qual o professor faz um diagnóstico e atua como mediador da aprendizagem do aluno, neste enfoque são empregados instrumentos de avaliação (BATISTA, 2007, p. 123, grifo do autor).

Tacoshi e Fernandez (2008) relataram em sua pesquisa que professores consideram o ensino por memorização uma prática inadequada que não leva ao aprendizado, porém aceitam em atender as demandas dos exames de vestibular, valorizados pela sociedade como um exame que realmente dimensiona o conhecimento, e Ferreira et al. (2009, p. 1) evidenciaram entre os graduandos da Universidade Federal de Sergipe acerca do tema avaliação da aprendizagem que o discurso vigente 
é o de que a avaliação é autoritária e que este tema não é discutido dentro da sala de aula, havendo dessa forma um distanciamento entre o processo de ensino aprendizagem e o ato de avaliar, e afirmaram ainda que verdadeiramente as avaliações realizadas não retratam o aprendizado real.

Preite (2010, p. 25) descreveu que as provas escritas ainda são a prática mais frequente nas escolas. Buscando uma reflexão a cerca dos constantes fracassos e reprovações atribuídos aos alunos, foi realizado um levantamento junto a professores da rede pública estadual de ensino a cerca das suas concepções de avaliação de aprendizagem. Ao que parece, todos os professores entrevistados, mesmo se aproximando, em alguns momentos, de uma avaliação mais formativa, tentando verificar os erros dos alunos, ajudando-os a superá-lo, na maior parte do tempo, tendem a empregar uma avaliação mais tradicional, utilizando provas escritas e atribuindo notas, também, ao comportamento dos alunos em sala de aula.

Camargo (2010, p. 13) investigou o cotidiano educacional de uma escola de Ensino Fundamental de Londrina no Paraná, que Ihe permitiu diagnosticar que a avaliação é voltada exclusivamente para a classificação, tendo a nota como aspecto principal, atribuindo a esta um caráter de disciplinamento sendo utilizado como um instrumento punitivo, de ameaça e julgamento. Observou também que apesar dos professores possuírem concepções inovadoras acerca da avaliação, sentem dificuldades em modificar sua postura em sala de aula, caracterizando mais uma vez a contradição eminente entre o discurso e a prática, pois apesar da grande maioria dos docentes reconhecerem a importância da avaliação formativa e não classificatória, a prática revela o contrário.

Melo et al. (2012) verificaram que uma minoria de professores de Ciências Naturais cursando a segunda licenciatura em Ciências da Natureza e Matemática do Instituto Federal do Rio Grande do Norte aplicam instrumentos avaliativos com função diagnóstica no inicio do ano letivo, porém não há uma preocupação com a identificação de habilidades já construídas pelos alunos e os dados coletados não são utilizados para a construção dos seus planejamentos; ou seja, esta não atinge todas as suas potencialidades, uma vez que se constitui de um ato isolado e não integrado ao planejamento e desenvolvimento do curso, demonstrando que estes têm uma concepção fragmentada do processo avaliativo, o que pode influenciar o processo de ensino e aprendizagem no sentido de não alcançar os objetivos propostos.

Também buscando caracterizar as concepções e práticas de avaliação de professores de Ciências do Ensino Básico foram constatadas duas concepções por Correia e Freire (2014, p. 403), uma que descreve uma avaliação da aprendizagem primordialmente de caráter somativa e outra que afirma que a avaliação da aprendizagem tem por fim promover uma avaliação orientada para a melhoria das aprendizagens, valorizando o caráter formativo da avaliação. Relativamente às práticas avaliativas verificou-se que os critérios não são explicitados aos alunos, o feedback é pouco frequente e os alunos têm um papel reduzido no processo de avaliação. Todos os professores pesquisados demonstram dificuldades na avaliação das competências cognitivas, sendo que, apenas um dos participantes elabora registros de observação para avaliar estas competências. Estudantes e Gestores do Ensino Fundamental de Salvador - BA também relataram suas experiências relacionadas ao processo de avaliação de sua aprendizagem. Os estudantes consideram a avaliação como um instrumento de verificação tradicional com sobrecarga emocional e estressante apesar da escola pesquisada possuir proposta pedagógica humanista e gestores capacitados pedagogicamente (SASAKI et al., 2014, p. 77, grifo do autor).

Considerando que a avaliação fará parte da formação docente e reconhecendo a importância desta, como instrumento de mediação na relação professor-aluno é que Fanelli (2012, p. 112) estudou a forma como a avaliação mediadora está inserida no nível superior do curso de Licenciatura em Ciências Biológicas. Nessa investigação, os pesquisadores verificaram que tanto os professores que cursaram licenciatura quanto os bacharéis não apresentam concepções claras quanto à 
avaliação mediadora. Além disso, foi observado que as práticas avaliativas dos docentes entrevistados mostraram-se incoerentes com suas falas, pois apesar de terem mencionado algumas ideias que envolvem a avaliação mediadora, revelaram não aplicá-las em seu cotidiano docente.

A literatura descreve também várias práticas de avaliação inovadoras que podem auxiliar os educadores a tornar esse processo menos traumatizante e mais humanizado para os educandos.

Com o objetivo de procurar respostas para o baixo rendimento apresentado por alunos nas disciplinas básicas dos cursos de Engenharia, foi realizado um projeto de avaliação diagnóstica relativo aos conteúdos de física, química e matemática, com os acadêmicos ingressantes nestes cursos. Esta pesquisa abordou de maneira particular as falhas na construção de competências em química de alunos que cursam os primeiros semestres de Engenharia de Materiais, os quais demonstraram que de fato os alunos ingressantes nos cursos de Engenharia não apresentam um nível satisfatório de conhecimento em química que permita sua evolução nas disciplinas pertinentes aos primeiros anos do curso. O projeto realizado objetivou além do diagnóstico, melhorar a qualidade do ensino ofertado através do aumento de motivação ao mesmo tempo em que tornou os envolvidos conscientes da realidade pedagógica vivida nesta disciplina, e com isso possibilitar a tomada de ações por parte do corpo docente no sentido de tentar diminuir a evasão dos alunos que ocorre principalmente nos primeiros anos dos cursos de Engenharia (MARMO; OLIVEIRA, 2005).

Uma experiência de avaliação continuada foi implementada na disciplina Gestão de Pessoas, do curso de graduação em Administração da Faculdade Estácio de Sá de Juiz de Fora - MG. Por esta verificou-se um aumento expressivo nas notas e no desempenho dos alunos, fato atribuído primordialmente ao aumento do tempo dedicado aos estudos da matéria lecionada na disciplina, provocando nos pesquisados um aprendizado mais efetivo. É fato, que há um acréscimo significativo da carga de trabalho neste sistema pelo grande número de provas a serem elaboradas e corrigidas, exigindo também do docente uma maior dedicação de tempo, o que pode caracterizar-se como um complicador na implementação dessa metodologia, sendo necessário a alocação de um maior número de aulas para a realização das provas. A despeito das limitações docentes, a experiência relatada indicou claramente a importância de que sejam buscadas alternativas às formas tradicionais de avaliação do aprendizado objetivando a melhoria do processo ensino aprendizagem (GRIZEND; SILVA; FERREIRA, 2008, p. 1).

A avaliação formativa é um instrumento de diagnóstico do processo de ensino aprendizagem que fornece informações sobre a qualidade e o curso da construção do conhecimento. Ao programar estratégias formativas de avaliação durante o processo de ensino aprendizagem da disciplina de Química inorgânica I, para discentes licenciandos em química da Universidade Federal de Pernambuco foram estabelecidas metas cognitivas a serem alcançadas e utilizada uma realimentação interativa, caracterizado como um acompanhamento contínuo durante a construção do conhecimento. Os resultados obtidos sugeriram que a metodologia pedagógica implantada foi bem sucedida no diagnóstico e mediação do processo de construção do conhecimento apesar de as metas cognitivas terem sido só parcialmente alcançadas. Estes estudos sugerem que discentes com dificuldades de aprendizagem que são ensinados através de estratégias de auto-regulação geralmente apresentam um aumento significativo no rendimento outrora verificado. Com efeito, foi possível, através da avaliação formativa, monitorar e orientar o desempenho dos discentes ao longo do tempo em múltiplas situações de resolução de problemas, atuando como ente motivador para o ensino aprendizagem (LARANJEIRA; OLIVEIRA, 2012, p. 5001).

Rausch, Silva e Theiss (2012, p. 6) também descreveram uma prática de avaliação formativa realizada na disciplina de matemática financeira com alunos de graduação. Essa experiência envolveu a elaboração do Programa de Ensino que foi precedida de uma avaliação diagnóstica. A experiência se deu pela condução sistemática de avaliações formativas, feedbacks e autoavaliação 
dos alunos. Os resultados obtidos indicaram que, no caso analisado, o professor estabeleceu meios para concretizar o que a literatura descreve como relevante para transformação da avaliação em um processo de aprendizagem. Ao chamar os alunos a assumirem junto com o professor a responsabilidade pela sua aprendizagem, o professor os conduziu para a emancipação, em que o aluno cresce como pessoa e a sociedade ganha, pois passa a conviver com um cidadão crítico e responsável.

Nota-se pelas experiências relatadas por estudantes, educadores e coordenadores que marcadamente ainda prevalece o modelo tradicional de avaliação no qual a prova ainda é preconizada como único instrumento avaliativo. Esse método avaliativo preconiza e valo $\urcorner$ riza a memorização dos conteúdos e o acúmulo de conheci ᄀmentos quase sempre sem conexão com o cotidiano e os conhecimentos prévios dos alunos. Notamos ainda, que mesmo que o sistema educacional apresente uma proposta pedagógica diferenciada, que os educadores tenham formação continuada

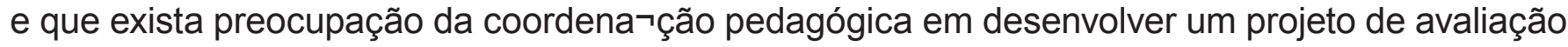
pau ᄀtado em princípios pedagógicos consolidados, o método avaliativo continua ficando de fora desse plano pedagógico no sentido de se manter estático e sem inovações. Neste modelo não são considerados importantes o momento e o modo de avaliar.

Assim, entende-se que há a necessidade de envolver todos os sujeitos participantes do processo de aprendizagem no desafio de desenvolver uma avaliação que tenha como princípio norteador o aumento do aprendizado no qual o aluno seja levado a pensar, refletir, criticar, elaborar conceitos, superar dificuldades, desenvolver autonomia e não na pedagogia do esforço e recompensa onde a avaliação se dedica simplesmente à geração de notas, tornando-se dessa forma um mecanismo de exclusão.

Os modelos de avaliação devem promover a aprendizagem significativa, a construção coletiva do conhecimento, a exploração do raciocínio lógico, o estímulo à capacidade crítica e reflexiva, o exercício da oralidade e da expressão de pensamentos, a elaboração de hipóteses e a discussão saudável e profícua, tornando o aluno sujeito do seu conhecimento e não objeto dele. Daí a grande importância de se ter consolidado o processo de construção do conhecimento pautado na aprendizagem significativa, e o foco não seja somente nos conteúdos ou nas cobranças do cumprimento das tarefas fruto de uma prática coercitiva, opressora e cerceadora de pensamentos, mas que esta seja um ato democrático, prazeroso, que contemple os interesses dos alunos em relação aos instrumentos avaliativos utilizados, respeitando o seu ritmo de aprendizagem e de modo especial seja um momento de diagnóstico e de progressão.

É fato que a implementação de novos métodos e técnicas avaliativas dispensa maior empenho e dedicação requerendo uma atenção diferente da costumeiramente exigida em um processo de avaliação tradicional, porém é notório o sucesso pelo aumento significativo dos níveis de aprendizagem.

\section{3 | UM OLHAR SOBRE OS INSTRUMENTOS AVALIATIVOS}

Os instrumentos avaliativos da aprendizagem devem ser meios capazes de oportunizar ao docente um diagnóstico/perfil da realidade educacional, através do qual ele será capaz de traçar novas rotas, alterar metodologias ou buscar estratégias que ratificam ou retificam as metodologias educacionais até então adotadas.

A avaliação da aprendizagem segundo Luckesi (1995) consiste de um ato amoroso, ao passo que deve funcionar como um ato acolhedor, integrativo e inclusivo, dessa forma o ato de avaliar, estar a serviço da obtenção do melhor resultado possível sendo capaz e estando disponível para o acolhimento da realidade tal como ela se apresenta. (LUCKESI, 2005). Neste enfoque, os instrumentos 
avaliativos se caracterizam por um conjunto de técnicas que possam prover o docente com dados fiéis da realidade a ser diagnosticada.

Vários autores dão conta que o principal instrumento avaliativo utilizado é a prova, atribuindo a esta características específicas de acordo com a realidade educacional em que vivem. Tacoshi e Fernandez (2008) afirmaram que esta tem o papel de certificação, cumprindo a função social de prestação de contas aos alunos e pais e não tendo como objetivo a promoção da aprendizagem e Correia e Freire (2014, p. 403) também relataram a aplicação de testes como principal instrumento de avaliação nas aulas dos professores participantes de um estudo, o que é coerente com uma concepção de ensino e aprendizagem ainda, marcadamente tradicional.

Outros instrumentos foram relatados em pesquisas relacionadas, porém, nenhum deles é aplicado por seu papel integrativo. Ferreira et al. (2009, p. 1) constataram que além das avaliações como instrumentos mais populares de avaliação são utilizados seminários expositivos, resultado da prática de copiar e colar de fontes bibliográficas nem sempre confiáveis. Além desses, Camargo (2010, p. 15) relatou o uso de trabalhos (individuais ou em grupo) e pesquisas, instrumentos que tais como os seminários são fruto de uma prática muito duvidosa de dissertação. Alunas do quarto ano do curso de Pedagogia descreveram em pesquisa realizada por Oliveira e Paixão (2013) que primordialmente em seu curso também são aplicadas provas como instrumentos avaliativos, mas relatam nesta pesquisa a sugestão de alunos para a aplicação de ferramentas descritas pelos mesmos como mais participativas e integradoras, tais como seminários, trabalhos ou avaliação oral, porém sabe-se que na maioria das vezes estes instrumentos não cumprem a função necessária, mas são tidas como instrumentos acreditadamente mais fáceis do ponto de vista dos alunos graças à má aplicação das mesmas.

Sendo a linguagem e a escrita as ferramentas preponderantes no processo de avaliação, estas carecem de um olhar sensível e comprometido. Desse ponto de vista, torna-se necessário tecer uma análise sobre esses instrumentos. Como forma de avaliar a linguagem dominante em alunos do Ensino Médio, foi realizada uma oficina didática cujo tema era reação química. Os alunos participantes desta oficina foram chamados a realizarem atividades de avaliação qualitativa e quantitativa sobre os conhecimentos prévios e os adquiridos depois da realização da oficina sobre o tema em questão. Os resultados dos ins ᄀtrumentos de avaliação empregados apontaram para uma predominância do uso da linguagem cotidiana e coloquial pelos alunos para explicar as transformações químicas (SANTOS et al., 2013, p. 3195). Ainda no intuito de produzir conhecimento sobre avaliação, utilizando como instrumento a produção escrita dos alunos, é que esta foi avaliada através da produção de texto por um grupo de alunos de um colégio estadual de Ensino Médio de Porto Alegre ao longo do primeiro semestre de 2004 nas aulas de química. Sobre esses dados foi procedida uma análise textual qualitativa, que permitiram classificar os textos em três categorias principais de acordo com a mensagem transmitida: evolução no entendimento dos conceitos estudados, uma tomada de consciência da relevância do estudo desses conceitos e um crescente inter-relacionamento do conhecimento científico com o cotidiano. A avaliação, por meio da produção escrita, mostrou-se eficiente no diagnóstico das facilidades e dificuldades do processo de aprendizagem e do desenvolvimento de competências relacionados ao ensino de química desse grupo de alunos (MOREIRA, 2005, p. 107).

Buscando entender e melhorar o processo avaliativo em educandos em nível de $8^{\circ}$ série de escolas públicas de Santa Catarina, é que foram investigadas as habilidades e atitudes científicas, empregando-se instrumentos de avaliação hierarquizados em categorias do conhecimento científico, tais como: empregar símbolos e convenções científicas, empregar aparelhos e instrumentos de medidas, fazer observações, interpretar e aplicar conceitos científicos e planejar e executar experimentos. Tais pressupostos são necessários ao bom desempenho dos alunos no ensino de 
Ciências Naturais. Nesse processo avaliativo foram aplicados testes teóricos que variavam de simples múltipla escolha, preenchimento de lacunas, questões dissertativas com situações de levantar hipóteses e inferências e testes práticos que variavam da manipulação de instrumentos simples, como um termômetro, até a resolução de um problema. Em todos os testes as devidas informações eram fornecidas e muitos diziam respeito ao dia-a-dia dos respondentes. Os resultados obtidos demonstraram um baixíssimo desempenho dos alunos principalmente nos testes práticos e em especial na habilidade de resolver problemas, confirmando a hipótese dos pesquisadores de que o ensino nesta área de saber é pobre na capacidade de conduzir os educandos a elaborar, interpretar, fazer inferências e aplicar conhecimentos em novas situações, ou seja, o ensino é dogmático e memorístico. Porém, o método se mostrou excelente em promover uma avaliação diagnóstica, sendo que revelou com precisão o objeto avaliado (ZUNINO, 1991, p. 170).

Com o intuito de explorar e analisar as possibilidades do uso do lúdico como uma ferramenta para a realização da avaliação da aprendizagem de determinados conceitos químicos na Universidade Federal de Goiás é que Cavalcanti (2011, p. 193) utilizou jogos e experimentos nesse processo. Neste intuito foram utilizados jogos, Perfil Químico e outro de autoria do grupo de pesquisa, e o desenvolvimento e gravação de vídeos de experimentos realizados pelos alunos. Os resultados mostraram que é possível trabalhar o lúdico na avaliação da aprendizagem, principalmente formativa e diagnóstica, podendo utilizar essa ferramenta antes ou depois de uma aula, trabalhando com a interatividade aliada a diversão proporcionando discussões entre os alunos, e entre os alunos e o professor na busca de minimizar problemas conceituais e tornar o Ensino de Química mais atrativo e relevante para o aluno, além de fazer com que os alunos revejam conteúdos não apreendidos e compreendidos, tendo em vista que em uma prova ou exame comumente não existe a possibilidade de voltar em conteúdos já ensinados pelo professor. A atividade lúdica pode mostrar a aplicabilidade de determinados conteúdos, ou seja, trabalhar com a contextualização e principalmente com a interdisciplinaridade tentando relacionar os assuntos principalmente das ciências naturais e Matemática.

Ainda nesta linha, Silva e Amaral (2011, p. 2) apresentam uma experiência realizada em uma escola pública de São Paulo que utilizou a construção de jogos pelos alunos como instrumento de avaliação da aprendizagem na disciplina de Ciências. Participaram dessa experiência trinta e cinco (35) alunos da oitava série do Ensino Fundamental. O processo de avaliação ocorreu durante e após a construção dos jogos, pois os mesmos foram trocados e jogados entre eles. O conteúdo escolhido pelos alunos para a construção foi o olho humano e sua estrutura. Os resultados dessa experiência mostraram que a ação pedagógica avaliativa realizada por meio do desenvolvimento dos jogos apresentou-se como excelente instrumento avaliativo, caracteristicamente informal, porém não representando prejuízo para os objetivos desta. Os autores concluíram também que é possível realizar a avaliação através da elaboração de jogos para além da classificação, mas formativa, pois a referida atividade esteve alicerçada em objetivos claros, simples, precisos, e que conduziram a uma efetiva concretização da aprendizagem.

A avaliação de aprendizagem foi testada como uma metodologia dita inovadora pelos experimentadores na forma de elaboração e apresentação de colóquios acerca de temas tratados na disciplina de Laboratório de Química Analítica Qualitativa. Esse procedimento induziu o aluno a construir o conhecimento pesquisando em fontes diversas para preparar a aula e, preparar-se para a apresentação dos colóquios e possíveis discussões que poderiam surgir durante a sua exposição. Esta metodologia pode ser comparada ao método de indução socrático, no qual o aluno é colocado diante de questões referentes a assuntos até então desconhecidos por ele e o mesmo é chamado a buscar novas fontes de conhecimentos para a resolução do "problema", precisando para isto recorrer a conhecimentos que, muitas vezes já estavam caminhando para o esquecimento e também 
fazer o elo entre disciplinas que até então seguiam separadas. Essa forma de avaliar o aprendizado do aluno está de acordo com a abordagem construtivista, pois é baseada, entre outras, nas investigações pela descoberta e a coleta de dados avaliativos que se baseiam mais sobre a atitude dos alunos sobre as questões apresentadas do que sobre os resultados, sendo considerada, por fim, uma avaliação diagnóstica e formativa (AL-ASFOUR et al., 2007, p. 55, grifo do autor).

\section{4 | CONSIDERAÇÕES FINAIS}

ICupolillo (2007, p. 51, grifo do autor) aproximando a obra de Paulo Freire ao que se pretende da avaliação da aprendizagem baseou-se em três categorias marcadamente presentes na obra desse ícone do construtivismo, o diálogo, o conhecimento e o inacabamento. O dialogismo como metodologia pressupondo relações democráticas entre sujeitos históricos que, necessariamente, possuem conhecimentos que devem ser compartilhados; o conhecimento como sendo fruto de uma construção dinâmica que se dá no embate cotidiano entre sujeitos históricos e o inacabamento remetendo a discussão da avaliação à ideia de processo, redimensionando o debate sobre os instrumentos e critérios utilizados, pois se somos necessariamente inacabados, em processo constante de construção, o viés punitivo, seletivo e excludente da avaliação da aprendizagem escolar perde o sentido.

Conclusivamente, verificamos que apesar da existência de experiências, propostas e soluções possíveis para o estatismo que a avaliação da aprendizagem ainda representa para o desenvolvimento e avanços necessários nos sistemas educacionais, esta ainda é caracteristicamente retrógada, conservadora e ultrapassada para o que se pretende como objetivos gerais do ensino institucionalizado nos documentos curriculares nacionais e nas necessidades modernas e atuais dos educandos.

Pelo levantamento realizado, torna-se evidente que a incompatibilidade entre o discurso e a prática docente na maioria dos casos pesquisados não são justificadas, o que torna ainda mais urgente a necessidade de um olhar direcionado a essa realidade a fim de oportunizar aos discentes do nosso tempo instrumentos avaliativos mais humanizados, atuais e coerentes com o discurso e a legislação. 


\section{Referências}

AL-ASFOUR, S. V. et al. Uma metodologia inovadora para avaliação em laboratório de química analítica qualitativa: uma análise da eficiência no processo ensino-aprendizagem. Revista Experiências em Ensino de Ciências, v. 2, n. 1, p. 55-56, 2007.

BATISTA, H. M. de A. A prática pedagógica dos professores do ensino médio do CEFET - PI: desvelando concepções de avaliação da aprendizagem. 2007. 158 f. Dissertação (Mestrado em Educação)- Universidade Federal do Piauí, Teresina, 2007.

BRASIL. Ministério da Educação e do Desporto. Secretaria de Educação Fundamental. Parâmetros curriculares nacionais: introdução aos parâmetros curriculares nacionais. Brasília, DF: MEC; SEF, 1997a. 126 p. v. 1.

Ministério da Educação e do Desporto. Secretaria de Educação Fundamental. Parâmetros curriculares nacionais: ciências naturais. Brasília, DF: MEC; SEF, 1997 b. 136 p. v. 4.

Ministério da Educação e do Desporto. Secretaria de Educação Fundamental. Parâmetros curriculares nacionais: terceiro e quarto ciclos do ensino fundamental: introdução aos parâmetros curriculares nacionais. Brasília, DF: MEC; SEF, 1998a. 174 p.

Ministério da Educação e do Desporto. Secretaria de Educação Fundamental. Parâmetros curriculares nacionais: terceiro e quarto ciclos do ensino fundamental: ciências naturais. Brasília, DF: MEC; SEF, 1998b. 138 p.

BRITO, R. M. C. O professor, a aprendizagem significativa e a avaliação: base para o sucesso escolar do aluno. In: SEMINÁRIO REGIONAL DE POLÍTICA E ADMINISTRAÇÃO DA EDUCAÇÃO DO NORDESTE, 7., 2012, Recife. Anais... Recife: ANPAE, 2012. (Série cadernos ANPAE, n. 13).

CAMARGO, W. F. Avaliação da aprendizagem no ensino fundamental. 2010. 101 f. Trabalho de Conclusão de Curso (Curso de Pedagogia) - Universidade Estadual de Londrina, Londrina, 2010.

CAVALCANTI, E. L. D. O lúdico e a avaliação da aprendizagem: possibilidades para o ensino e a aprendizagem de química. 2011. 171 f. Tese (Doutorado em Química)Universidade Federal de Goiás, Goiânia, 2011.

CORREIA, M. S. M.; FREIRE, A. M. M. S. Concepções e práticas de avaliação de professores de ciências físico-químicas do ensino básico. Investigações em Ensino de Ciências, v. 19, n. 2, p. 403-429, 2014.
CUPOLILLO, A. V. Avaliação da aprendizagem escolar e o pensamento de Paulo Freire: algumas aproximações. Práxis Educativa, v. 2, n. 1, p. 51-64, 2007.

FANELLI, M. A. A avaliação mediadora sob o olhar de professores do Ensino Superior. 2012. 100 f. Monografia (Curso de Ciências Biológicas) - Universidade Presbiteriana Mackenzie, São Paulo, 2012.

FERREIRA, A. S. et al. Avaliação da aprendizagem no ensino superior. In: COLÓQUIO INTERNACIONAL DE EDUCAÇÃO E CONTEMPORANEIDADE, 3., 2009, Itabaiana. Anais... Itabaiana: UFS, 2009. p. 1-12.

GRIZENDI, J. C. M.; SILVA, J. A. O.; FERREIRA, V. C. $P$. A contribuição da avaliação continuada para a melhoria do desempenho discente: relato de uma experiência. Estação Científica Online, n. 6, p. 1-14, 2008.

LARANJEIRA, J. M. G.; OLIVEIRA, S. F. Avaliação formativa no ensino de química: sequenciando a aprendizagem em construção. In: ENCONTRO NACIONAL DE DIDÁTICA E PRÁTICAS DE ENSINO, 16., 2012, Campinas. Anais... Campinas: UNICAMP, 2012. p. 5001-5012.

LUCKESI, C. C. Avaliação da aprendizagem escolar: estudos e proposições. São Paulo: Cortez, 1995.

Avaliação da aprendizagem na escola: reelaborando conceitos e criando a prática. 2 ed. Salvador: Malabares Comunicações e Eventos, 2005.

MARMO, A. M. B.; OLIVEIRA, A. H. Análise dos resultados da avaliação diagnóstica em química realizada com alunos do curso de engenharia de materiais. In: CONGRESSO BRASILEIRO DE ENSINO DE ENGENHARIA, 33., 2005, Campina Grande. Anais... Campina Grande: UFCG, 2005.

MELO, A. C. O. et al. A função diagnóstica da avaliação: uma atividade em construção. In: CONGRESSO NORTE NORDESTE DE PESQUISA E INOVAÇÃO, 7., 2012, Palmas. Anais... Palmas: IFTO, 2012.

MOREIRA, M. A. O. Avaliação da aprendizagem em química no ensino médio: a produção escrita como instrumento. 2005. 103 f. Dissertação (Mestrado em Educação) - Pontifícia Universidade Católica do Rio Grande do Sul, Porto Alegre, 2005.

OLIVEIRA, J. D. de; PAIXÃO, P. C. M. Avaliação no ensino superior: modalidades, funções e instrumentos avaliativos no processo de ensino e aprendizagem. In: ENCONTRO INTERNACIONAL DE PRODUÇÃO CIENTÍFICA CESUMAR, 8., 2013, Maringá. Anais Eletrônico... Maringá: CESUMAR, 2013. 
PREITE, N. Z. A avaliação nos processos de ensino e aprendizagem: concepções de professores da rede pública de ensino. 2010. $73 \mathrm{f}$. Monografia (Curso de Ciências Biológicas) - Universidade Presbiteriana Mackenzie, São Paulo, 2010.

RAUSCH, R. B.; SILVA, M. Z.; THEISS, V. Avaliação formativa no processo ensino e aprendizagem na educação superior: um estudo de caso realizado na disciplina de matemática financeira. In: ENCONTRO DA ASSOCIAÇÃO NACIONAL DE PÓS-GRADUAÇÃO E PESQUISAS EM ADMINISTRAÇÃO, 36., 2012, Rio de Janeiro. Anais... Rio de Janeiro: ANPAD, 2012. p.1-16.

SANTOS, B. F. dos et al. Aprendendo a ensinar química: a importância da avaliação na realização de uma oficina didática com professores em formação. In: CONGRESO INTERNACIONAL SOBRE INVESTIGACIÓN EN DIDÁCTICA DE LAS CIÊNCIAS, 9., 2013, Girona. Anais... Girona: [s.n.], 2013. p.3195-3199.
SASAKI, K. et al. Percepções de estudantes do ensino fundamental sobre sua avaliação de aprendizagem. Revista Quadrimestral da Associação Brasileira de Psicologia Escolar e Educacional, São Paulo, v. 18, n. 1, p. 77-86, jan./abr. 2014.

SILVA, T. C.; AMARAL, C. L. C. Jogos e avaliação no processo ensino-aprendizagem: uma relação possível. REnCiMa, v. 2, n. 1, p. 1-8, jan./jun. 2011.

TACOSHI, M. M. A.; FERNANDEZ, C. Ideias sobre avaliação da aprendizagem em química e o modelo didático implícito de professores. In: ENCONTRO NACIONAL DE ENSINO DE QUÍMICA, 14., 2008, Curitiba. Resumos... Curitiba: UFPR, 2008. p. 1-10.

ZUNINO, A. V. Avaliação diagnóstica do ensino de ciências naturais em nível de $8^{\mathrm{a}}$ série. Perspectiva, v. $9, \mathrm{n}$. 16, p. 170-184, 1991. 